\title{
A Blended Learning Course Design in Clinical Pharmacology for Post- graduate Dental Students
}

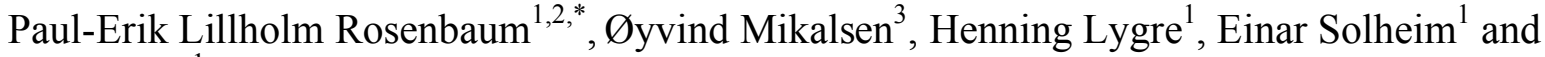 \\ Jan Schjøtt ${ }^{1}$ \\ ${ }^{1}$ Section of Pharmacology, Institute of Medicine, Faculty of Medicine and Dentistry, University of Bergen, Norway \\ ${ }^{2}$ Sjukehusapoteka Vest HF, Bergen, Norway \\ ${ }^{3}$ Department of Chemistry, Faculty of Mathematics and Natural Sciences, University of Bergen, Norway
}

\begin{abstract}
Postgraduate courses in clinical pharmacology are important for dentists to be updated on drug therapy and information related to their clinical practice, as well as knowledge of relevant adverse effects and interactions. A traditional approach with classroom delivery as the only method to teaching and learning has shortcomings regarding flexibility, individual learning preferences, and problem based learning (PBL) activities compared to online environments. This study examines a five week postgraduate course in clinical pharmacology with 15 hours of lectures and online learning activities, i.e. blended course design. Six postgraduate dental students participated and at the end of the course they were interviewed. Our findings emphasize that a blended learning course design can be successfully used in postgraduate dental education. Key matters for discussion were time flexibility and location convenience, change in teacher's role, reinforced learning strategies towards professional needs, scarcity in online communication, and proposed future utilization of e-learning components.
\end{abstract}

Keywords: Educational design, e-learning, blended learning, learning management system (LMS), dental education, problem based learning (PBL).

\section{INTRODUCTION}

Dentists need postgraduate education in clinical pharmacology for several reasons. Administration of local anaesthetics and the prescribing of analgesics and antibiotics are classical examples [1]. However, older patients are associated with polypharmacy, and knowledge of drug interactions and adverse effects that cause dental problems are important [2] Furthermore, there is an increased use of psychotropic drugs in the younger population, and some of these drugs affect oral hygiene, either directly or indirectly through behavioural effects [3] Moreover, nutritional and herbal medicine have been demonstrated to affect drugs sensitive to interactions: a relevant example is warfarin, with increased risk of bleeding [4]. Thus, continuous learning in pharmacology is important for dentists, but the optimal education strategy is yet to be defined.

The advent of new technologies has provided opportunities and challenges for new and different strategies of education and training, and new skills. More learner-centred activities and new theories of learning have led to increased options of teaching and learning. But first of all, the appearance of new technologies, information and communication technology (ICT) has become an inevitable part of modern

*Address correspondence to this author at the Section of Pharmacology, Institute of Medicine, University of Bergen, Norway;

Tel: +47 55977383; Fax: +47 552915 72;

E-mail: paul-erik.rosenbaum@sjukehusapoteka-vest.no education. Thanks to ICT a significant change in education already has taken place towards different types of education techniques and technologies [5].

In the past, the term e-learning referred to any method of learning that used electronic delivery systems. With the development of the internet however, e-learning has evolved and the term is now commonly used to refer to online courses. Over the past ten years the internet's influence on dental education has been evident [6]. E-learning exists as a completely independent form, but also as integral parts of traditional education, in which it is combined with face-toface instruction.

In the situation where e-learning is introduced as an aid to traditional teaching the term blended learning is most appropriate in explaining this method of instructional delivery [7]. Face-to-face interactions provide a social foundation, which is critical to online learning. Learners build relationships in the classroom environment, and are able to extend these in the online environment [8]. Thus blended learning has become a popular form of e-learning, very suitable in the process of transition from traditional forms of teaching and learning towards e-learning. According to the Centre for Educational Research and Innovation [9] blended learning strategies are increasing in prominence as ICTs are deployed to compliment rather than replace traditional forms for higher education learning.

This paper presents the first integration of information technology into an inaugural curriculum in clinical pharmacology at the University of Bergen. Ruiz et al., [10] recom- 
mend the integration of e-learning into curricula using a blended learning approach rather than moving entirely to a computer-based format. In this study we redesigned a former traditional course format into a combined structure of faceto-face classroom instructions and asynchronous e-learning activities. Previous research has reported this blended learning format to be successful in regard to dental students' learning experiences [11]. The format has also been found to be a more effective teaching approach compared to a pure elearning approach. Mortera-Gutiérres [12] discovered that when the face-to-face portions of blended learning courses were totally discarded, the teaching was ineffective. A favourable outcome from computer supported teaching methodologies in dental education has primarily been explained through the improved abilities of providing highly personalized learning content by the possibilities of matching various personal learning preferences [13] and by using the learning advantages that derive from the PBL educational format [14]. Furthermore, advantages like flexibility and convenience have contributed to successful experiences. Hughes et al. [13] make a call for research on postgraduate dentistry distance learning scenarios. They argue that the future will lead to an increased necessity towards web-based education for this particular target group. To address this gap in the literature our research study pilot-tested and evaluated a course titled "Clinical Pharmacology for Postgraduate Dental Students" developed and conducted at the Institute of Medicine at the University of Bergen, Norway. In postgraduate dental education, practical ICT activities in searching, analysing, and reflecting on information are equally important as theoretical ones. Moreover, it is important that dentists are familiarized with different aspects of e-learning, since dentistry is a science field where lifelong learning is essential. The learning activities of the course were linked to educational strategies of The Norwegian Dental Association toward continued professional development.

\section{METHOD}

The present study used the mix of traditional face-to-face instructions led by a teacher and online learning where the online portion was delivered via a Learning Management System (LMS) courseware.

\section{Settings}

The course "Clinical pharmacology for postgraduate dental students" is a part of the specialist training programme in dentistry at the Section of Pharmacology, Institute of Medicine, Faculty of Medicine and Dentistry, University of Bergen, Norway. The course reflects on clinical pharmacology pertaining to drugs commonly used in dental treatment. It is emphasized that participants become critical towards available drug information, and consequently develop abilities to demonstrate good understanding and reflection on issues regarding this specific field of dentistry. The educational strategy of using online information sources enables the participants to acquire useful information about various theories and practice within medical care for mandatory assignments of the course. Participants are introduced to explore various Norwegian drug information sources for health care professionals, including the database of the regional medicines and pharmacovigilance centres in Norway (RELIS). The RELIS database (www.relis.no/database), a web-based, full-text query-answer database for drug-related queries. Other sources included a database for drug-drug interactions for Norwegian clinicians (http://www.interaksjoner.no), the online version of the monographs in the national drug formulary, Felleskatalogen database (http://www.felleskatalogen.no), and the online version of general recommendations for drug therapy for various diseases in Norway, Norsk legemiddelhåndbok (http://www.legemiddelhandboka.no).

\section{The Blended Learning Course}

The course "Clinical pharmacology for postgraduate dental students" was prepared according to the sequential model of blended learning and online activities proposed by Koohang [7]. This model illustrates how transitioning from traditional teaching to a model of online learning can be conducted. A timetable of 4 three-hour face-to-face blocks, combined with 3 online blocks was decided to replace the traditional course structure of 15 hours of classroom teaching and a final exam. Each online block addressed the topics from the initial face-to-face block and included a mandatory assignment dependent on individual or collaborative activities. Each weekly online assignment was commented on and assessed by the course instructor. Three approved assignments were required to pass the course. Accordingly the final exam was substituted for the three assignments. Assignment \#1 asked students to write (and post on the discussion forum) a 500-word essay. The assignment text was as follows: "Define the term interaction. Give examples on interactions with clinical impact in contemporary dental practice". The second assignment was a peer assessment. The students had to read all colleagues' posts of assignment \#1. Every student had to choose two postings he/she liked (or could relate to) the most. Their job was to write a 300-word essay that included the reason for their choice, things they learned from the postings and thoughts, advice, reactions, and/or viewpoints regarding the postings. Students were encouraged to be positive and respect colleagues' viewpoints. The third assignment was a group activity where the students were divided into three groups. The groups were asked to write a 500word essay with the following questions: "How is the drug category analgesics described? And what impact do the descriptions have for contemporary clinical usage?" The assignments \#1 and \#3 used the PBL approach which focuses attention on real-world examples and stimulates critical thinking. Assignment \#2 was a peer assessment approach for promotion of learning among students and interpersonal understanding. All three assignments had to be approved by the instructor before a final course approval was verified. Fig. (1) shows important elements and progression of the course.

On completion of the course participants should be able to:

- explain what drug interactions are.

- identify various types on drug interactions.

- know where to find updated information of drug interactions.

- analyse and identify drug interactions to avoid adverse effects in their own dental clinic.

- apply good drug information procedures to own their patients. 


\section{Blended learning}

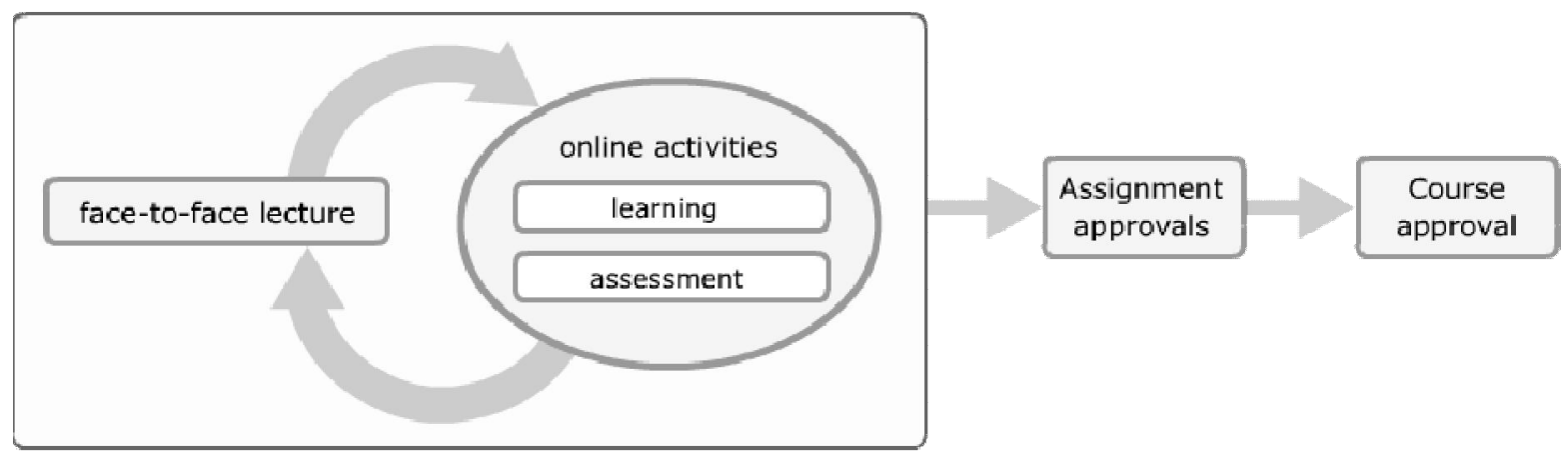

Fig. (1). Elements and progression in a blended learning course for postgraduate dental students at the University of Bergen, Norway.

The internet resources were delivered over a customized open-source LMS courseware. The features included student registration, the delivery of e-learning courses, a tracking system of students' activities, communication between students and teachers through chat rooms, an e-mail feature and forums. Further interactive modules enabled students to participate in online discussions. The LMS offered a range of software modules to help establish learning as an active and interactive process.

The online course content was produced into various formats compatible for the internet. These included html, .doc, and .pdf for the static content, and the mp4-format for the dynamic content. Narrated animations of the basic theories of general pharmacology were offered as multimedia instructions.

\section{Participants}

The study participants consisted of six $(n=6)$ postgraduate dentists ( 3 females, 3 males; age mean $=34$ years). All participants were accustomed to online content through other subjects in their postgraduate education. Only one participant had participated in a similar blended learning course before.

The research responds to a call by Koohang [7] for more research that can emphasize the uniqueness of using blended learning settings and investigate learners' attitudes towards blended courses, and/or learners' satisfaction. Measures should also include learners' opinions about the design of blended learning courses. This could contribute to enhancing the quality of blended learning designs and educational programmes.

\section{Data Collection}

At the end of the course an evaluation of the students was conducted via interviews. All six participants who attended the course were interviewed shortly after it ended. The interviews were semi-structured utilizing open-ended questions until new information was ascertained. The questions were formulated using the question from the first interview as a model. After each interview the statements were analyzed and discussed. Consequently the data analysis provided new guidelines for the subsequent interviews. Hence every interview became an action or call for change. The interviews were carried out in front of a video camcorder, and were transcribed for analysis. All participants were interviewed in Norwegian.
Before the data collection began, the purpose of the research and its implications were fully explained. Consent was given from all interviewees.

The analyses of comments from the interviews were put into three categories: structure and format of the course, participants' satisfaction, and identification of improvements. The categories were assumed to explain the values of the blended learning approach. Participants were assured anonymity in regard to their responses.

\section{RESEARCH QUESTIONS}

The main focus of this study is guided through the following questions:

1. What attitudes did the participants hold about the blended learning course from the perspective of their own satisfaction and perceived learning outcome?

2. What opinions did the participants hold that could improve courses in the future?

\section{RESULTS}

\section{Structure and Format of the Course}

The importance and potential of the course structure and format were emphasised in the students' comments. In general the participants liked the blended learning structure. Primarily enhanced flexibility, convenience, and time efficiency were reflected as benefits in the participants' comments. Further it was mentioned that online learning activities helped to change the role of the teacher from being a regular classroom instructor to a supportive facilitator (Fig. 2). The following bullet points list some of the comments that were made about the structure and format of the course:

- "It was much stronger than traditional classroom lessons with handouts. Here you had the opportunity to acquire information from home and prepare yourself for the lessons."

- "It's like taking the teacher home with you. Even on a Sunday afternoon, or when it suits you."

- "It is very crucial to offer courses like this when you are forced to work in your own practice beside for instance a full time study. You have to rationalize your time as much as possible." 


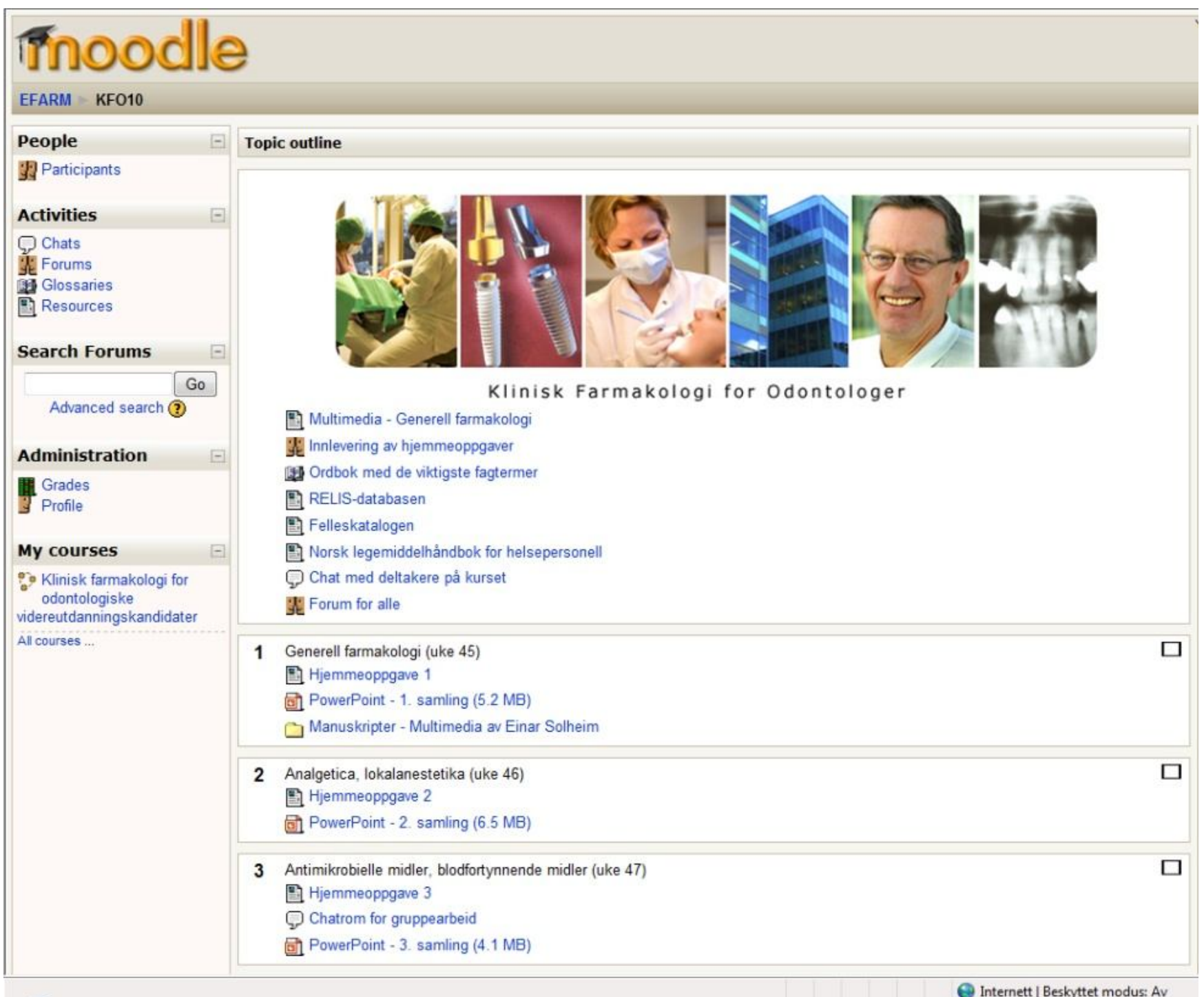

Fig. (2). A screen shot of the online course interface.

- "On one occasion I made my assignment at home [the participant lived 300 kilometres from the university] and delivered via the internet. I did not have to leave my practise. And if you count the financial benefits, it's quite a lot we talk about."

- "Sitting for several hours in a classroom and listening to a person talking can be very exhausting. Very soon you feel full. With this concept you can use your time more efficiently to find the information you really are searching for."

- "This course gave me the ability to get the content repeated more often. It's very important for me."

- "I am very satisfied with this course as a start. There are always disadvantaged with new things. I am very satisfied with the prospective possibilities, because there will always be a potential for development."

- "In reality it is like a revolution, because you can obtain much more selective information and use the teacher as a supervisor more than a traditional teacher".

\section{Participants' Satisfaction}

The participants valued the use of internet based online applications. Further they expressed the opinion that the course was a good initiative, and that they appreciated the ease of use.

\section{Identification of Improvements}

One of the objectives of this study was to identify improvements that could enhance the quality of subsequent courses. Feedbacks from the participants revealed a consensus of shared viewpoints in order to improve the function of the internet. The various proposals revolved around using the internet as an absolute repository for all teaching and learning activities, to reduce the number of classroom settings by replacing them with video conferences. The background for these proposals was to improve the quality of mandatory assignments towards PBL-based framework to meet specific professional needs, and not to require students to use online social media (Web 2.0). The participants deemed the potential of video software applications as being advantageous in 
this educational approach. The following bullet points list some of the comments that were placed in the identification of improvements category:

- "I think to a great extent, that I could have completed this course entirely on the internet."

- "The blended combination was good, but I think I could have accomplished more of the course via the internet, even to a greater extent."

- "You have to utilize this medium for all what it's worth. All information related to a course must be available on the internet."

- "I was missing a 'full package' [all teaching materials converted into online resources] solution."

- "I would prefer that the classroom lessons were video recorded; then we could bring down the number of the faceto-face sessions to two [from four]."

- "We didn't utilize the technology to a maximum. The meetings in the classroom were too often. Otherwise it was very good, much better than traditional teaching lessons."

- "It could be interesting to substitute some of the teacher-led instructions with video conferencing."

- "Assignment \# 2 (students had comment peer students posts) could have been changed into a more relevant task." tion."

- "The [social] communication in the system didn't func-

\section{DISCUSSION}

Flexibility and location convenience were key matters in postgraduate dental students' comments on a blended learning course. The feedback from the study was mainly positive. All students welcomed the course and expressed interesting recommendations for future course programs. Due to fact that the course was part of the specialist training programme in dentistry, the number of participants was low. However, our results suggest that blended learning course design can be successfully used in postgraduate dental education. Pahinis et al., [15] recorded a similar positive response among postgraduate dental students at the end of a blended learning course taught to different groups of learners in a dental school. They recorded an impressive positive difference between postgraduate students and other dental students. The blended learning format allowed participants to combine work, studies, and private life. Improved possibilities for anytime and anywhere freedom was considered as essential.

The issue of location convenience for professionals corresponds well with the use of distance learning to reduce the number of travelling hours to host institutions where courses in dentistry are undertaken. According to Shah \& Cunningham [16] research within the speciality of orthodontic education for postgraduates in Britain showed an increased tendency towards e-learning activities in remote areas mostly because of the timesaving issue. Hughes et al. [13] evaluated the challenges for dental residency programs in the US. Their finding similarly supports the importance of refining curricula towards more web-based formats since the physical presence of a teacher in rural districts may not always be possible. Thus it seems relevant to develop and incorporate distance learning formats particularly for postgraduate dentists located over various geographical distances.

The teacher-student relationship changed. Students responded positively so that the teacher was able to act more as a support for their learning activities instead of a person with expert knowledge. Combined with PBL these attitudes correspond well towards learner-managed learning expressed by Goodyear [17]. Rather than just a provider of answers and content the teacher becomes a guide, resource provider, and expert controller. The model refers to a change in teacher activity towards providing guidelines and creating learning environments where students are helped to arrive at their own conclusions.

The three mandatory assignments of the course were evaluated differently. Participants appreciated the PBL-tasks, but not the task of commenting on each other assignments. In fact a number of studies in medical education support learning by PBL $[18,19]$. Participants commented that the PBL assignments have a close relation to their professional requirements. Furthermore they expressed dissatisfaction with the assignment where they had to criticise the answer from a peer. They felt they had to spend time on a nonessential assignment. Obviously participants addressed learning priorities close to their current professional needs.

The Web 2.0 features of the LMS courseware including on-line discussion modules were not appreciated. Only a very low activity was registered. The interviewees commented that the features were not user-friendly. Moore \& Aspden [20] discovered that students on blended learning courses used on-campus face-to-face time to discuss subjects with other students instead of using online applications. It is possible that on-campus students do not value online communication when participating in blended learning courses. Students in other medical and dental courses have indicated that discussion boards were not well utilized [21]. Gupta et al. [22] realized that students were reluctant to communicate their views on the internet. They argued that students may consider on-line communication just as a supplement to traditional teaching and therefore have a preference of faceto-face interactions.

One of the main objectives of this study was to identify improvements that could be made to the courses in the future. Student opinions revealed a consensus in favour of improving the functionality of the internet as a repository for learning activities. Furthermore it was suggested teacher led classroom instructions be converted into video recorded ondemand controlled files or by replacing them with synchronous video conferencing. Bernett \& Glover [23] evaluated a teaching program for nurses with implementation of video recorded lectures of various topics. They concluded that the course had been "associated with positive student and teaching feedback suggesting that this technology may have improved learning experiences". The issue of substituting faceto-face interactions with video technology was studied by Jones et al. [24]. Participants found that synchronous live webcasting was a successful method in delivering medical instruction to postgraduate students. The approach is interesting and merit attention in future postgraduate course programmes in dentistry. 
A final issue worth mentioning was the students' reluctance for trying out unknown online resources before being instructed. Various useful drug databases were only slightly used before they were introduced in plenary session. A possible explanation could be that the specific databases were a little too sophisticated for new users.

\section{CONCLUSION}

Our findings suggest that a blended learning format can be successfully integrated into postgraduate dental education and provides a favourable transition to an enhanced flexibility, location convenience, and time efficiency. Informants expressed the opinion that e-learning combined with PBL activities helped to change the role of the teacher from being a regular classroom instructor to a supportive facilitator. There was no evidence of online social communication (Web 2.0).

Proposals for the next generation of blended learning courses were to enhance the function of the internet as an absolute repository for all teaching and learning activities and to minimize or even replace the number of classroom settings with online video-based features, for instance synchronous online video conferencing.

\section{CONFLICT OF INTEREST}

The authors confirm that this article content has no conflicts of interest.

\section{ACKNOWLEDGEMENT}

Declared none.

\section{REFERENCES}

[1] Dar-Odeh NS, Abu-Hammad OA, Al-Omiri MK, Khraisat AS, Shehabi AA. Antibiotic prescribing practices by dentists: a review. J Ther Clin Risk Manage 2010; 21: 301-6.

[2] Williams BR, Kim J. Medication use and prescribing considerations for elderly patients. Dental Clin North Am 2005; 49: 411-27.

[3] Persson K, Axtelius B, Söderfeldt B, Ostman M. Monitoring oral health and dental attendance in an outpatient psychiatric population. J Psych Mental Health Nurs 2009; 16: 263-71.

[4] Izzo AA, Ernst E. Interactions between herbal medicines and prescribed drugs: an updated systematic review. Drug 2009; 69: 177798.

[5] Köse U. A blended learning model supported with Web 2.0 technologies. Proc Soc Behav Sci 2010; 2: 2794-802.
[6] Garland KV. E-learning vs. classroom instruction in infection control in a dental hygiene program. J Dental Educ 2010: 74: 637-43.

[7] Koohang A. A learner-centred model for blended learning design. Int J Innovat learn 2009; 6: 77-91.

[8] Akkoyunlu B, Soylu MY. A study of students' perceptions in a blended learning environment based on different learning styles. Technol Soc 2008; 11: 183-93.

[9] CERI. E-Learning in Tertiary Education: Where do we stand? Paris: OECD Publishing 2005.

[10] Ruiz JG, Mintzer MJ, Leipzig RM. The impact of e-learning in medical education. Acad Med 2006; 81: 207-12.

[11] Retrouvey J, Finkenstein A. Blended learning in orthodontic diagnosis: an interactive approach. J Can Dent Assoc 2008; 74: 645-9.

[12] Mortera-Gutiérrez F. Faculty best practice using blended learning in e-learning and face-to-face instruction. Int J Distance Educ 2006; 5: 13-37.

[13] Hughes JM, Fallis DW, Peel JL, Murchison DF. Learning styles of orthodontic residents. J Dental Educ 2009; 73: 319-27.

[14] Smits PBA, Verbeek JHAM, Nauta MCE, Cate TJT, Metz JCM, van Dijk FJH. Factors predictive of successful learning in postgraduate medical education. Med Educ 2004; 38: 758-66.

[15] Pahinis K., Stokes CW, Walch TF, Tsitrou E, Cannavina G. A blended learning course taught to different groups of learners in a dental school: follow-up evaluation. J Dental Educ 2008; 72(9): 1048-57.

[16] Shah R, Cunningham SJ. Implementation of the virtual learning environment into a UK orthodontic training programme: the postgraduate and lecturer perspective. Eur J Dent Educ 2009; 13: 22332.

[17] Goodyear P. The ergonomics of learning environments: learnermanaged learning and new technologies. In: $3^{\text {rd }}$ Congress on New Information Technologies for Education. Malaga, Spain 1997; 717.

[18] Sackett DL, Richardson WS, Rosenberg W, Haynes RB. Evidencebased medicine: how to practice and teach. New York: Springer Publishing Company 1997.

[19] Boud D, Feletti G. The Challenge of problem based learning. London, U.K.: Kogan Page, 1998.

[20] Moore K, Aspen L. Coping, adapting, evolving: the student experience of e-learning. Library and Information Update 2004; 3: 22-4.

[21] de Leng BA, Dolmans DH, Muijtjens AM, van der Vleuten CP. Student perceptions of a virtual learning environment for a problem-based learning undergraduate medical curriculum. Med Educ 2006; 40: 568-75.

[22] Gupta B, White D, Walmsley AD. The attitudes of undergraduate students and staff to the use of electronic learning. Br Dent J 2004; 196: 487-92

[23] Bennett PN, Glover P. Video streaming: Implementation and evaluation in an undergraduate nursing program. Nurse Educ Today $2008 ; 28: 253-8$.

[24] Jones RB, Maramba I, Boulos MNK, Alexander T. Use of Live Interactive Webcasting for an International Postgraduate Module in eHealth: Case Study Evaluation 2009; Retrieved from: http://www.jmir.org/2009/4/e46/ [cited 20116 September]

\begin{tabular}{lll}
\hline Received: July 19, 2012 & Revised: September 06, 2012 Accepted: September 07, 2012
\end{tabular}

(C) Rosenbaum et al.; Licensee Bentham Open.

This is an open access article licensed under the terms of the Creative Commons Attribution Non-Commercial License (http://creativecommons.org/licenses/by-nc/3.0/) which permits unrestricted, non-commercial use, distribution and reproduction in any medium, provided the work is properly cited. 